\title{
Editorial: Collective entanglements in the doing of research
}

In this final issue of RERM in 2020, no less than 20 authors have participated in the materialization of four articles, which connect to each other in various ways. All of the articles focus upon productive relations, between authors, as well as between materials and people. Two of the contributions, the first written by Adams, Kerr and Wurzburg; and the next by Amos et al., provide insights into collective working and writing processes that both resonate and deviate to what is described by Deleuze and Guattari in the introduction to A Thousand Plateaus (1980/1987, p.3):

\footnotetext{
The two of us wrote Anti-Oedipus together. Since each of us was several, there was already quite a crowd. Here we have made use of everything that came within range, what was closest as well as farthest away. We have assigned clever pseudonyms to prevent recognition. Why have we kept our own names? Out of habit, purely out of habit. To make ourselves unrecognizable in turn. To render imperceptible, not ourselves, but what makes us act, feel, and think. Also, because it's nice to talk like everybody else, to say the sun rises, when everybody knows it's only a manner of speaking. To reach, not the point where one no longer says I, but the point where it is no longer of any importance whether one says I. We are no longer ourselves. Each will know his own. We have been aided, inspired, multiplied.
}

Deleuze and Guattari dwell on the moment when it is no longer of importance whether one says I, which beautifully captures the creative processes involved in collaborative writing and researching. The moments when you lose yourself, and expand, into other people, materials, texts and so on, creates forms of entanglements which are also highlighted in the articles by Restler, and Adams. Thus, all four articles illustrate the productiveness of moments in doing research that challenge the distinctions between researcher and researched, the concrete and the abstract, and the author and the text, arguably contrasting and adding humbleness to dominant academic structures centering the "researcher I" and its individual quest for qualifications.

The first article of this issue: "Rubbing the room: Tactile epistemologies of teacher work" is written by Victoria Restler from the US, who maps a site-specific research-creation project conducted at a New York City public school. The arts-based method of rubbing the room is presented as a tactile desire for intimacy, driven by the need to be re-connected and to close a gap which had emerged from being distanced from a research project initiated many years previously. Additionally, and in contrast to dominant de-contextualized, and abstract digital representations of teachers and teachers work, the rubbings are valued for their mimetic, analogue, life-sized and particular qualities. Instead of standardizations aiming to control both students and teachers, these rubbings produce potential for thick descriptions and intimacy, to differentiate and to learn with aberrations, subjectivities and 
entanglements. The project in its entirety, as well as the rubbings in their specificity, are regarded as assemblages, which are analyzed through a series of dialectical frames: Witnessing/ Evidence; Positioning/ Art; and Care/ Tactile epistemology. These three analytical frames highlight structural imbalances of power that are embedded in research relationships, which in turn opens for the multiplicity of meaning and co-constructions between researcher and researched. Moreover, the rubbings highlight other aspects of the daily work of the teacher and school spaces, and according to Restler, the practice of rubbing invites new emergences and arrangements of knowing, being with, and valuing, that resist dominant standardizations of control.

Next, Alison Warren uses Deleuze's concept of sense in her article entitled: "Framing emotions in early childhood teaching within Deleuze's concept of sense: Intensity and significance". Writing from the New Zealand context, she uses 'sense' to reconceptualize emotions and how they are in play in early childhood teaching. In contrast to taken-for-granted humanist perceptions of emotions as personal human possessions, emotions framed within the concept of sense are understood as prepersonal, complex and nuanced processes, emerging in networks of relations which are expressed both in language and in bodily changes. Further inspired by Deleuze and Guattari (1969/1990, 1980/1987), Warren uses concept-as-method to produce cartographies to map relations between encounters between Deleuze's writings and different data sources. For example, statements from an early childhood teacher, who takes responsibility for the daily sunscreen routine in an early childhood center provides the focus of analysis. Warren stresses that the professional responsibilities and actions by the teachers are entangled with intensities and significance, thus producing different emotions, expressions and experiences. Moving beyond good sense and common sense, towards paradox and nonsense, the need for innovative and creative responses to problems occurring in daily routines are illuminated. Her attention to pre-individual processes of sensing intensities and significance in early childhood teaching which are actualized through, for example resistance both from children and colleagues, are productively highlighted throughout the arguments presented in this article.

The third article: "She Embodied: A Materialized Collective", is written by a materialized collective she, comprising 14 graduate-students and one instructor from multiple research disciplines at the University of Memphis, USA. Asia Amos, Keishana Barnes, Tharwa Bilbeisi, JoAnna Boudreaux, Emily El-Oqlah, Noor Ghazal Aswad, Dorothy'e Gott, Rachel Hamilton, Tracy Hernandez, Clarie Koehn, Susan Naomi Nordstrom, Aailyah Shivers, Tiffinie Snowden and Hannah Tabrizi collaborated and collectively crafted this article as a means to grapple with what feminism means in contemporary educational contexts. The article materialized from discussions initiated during a feminist research course, which started with the question "What is your feminism?". The article is a production of doing unity differently, with the ability to include the sometimes uneasy, and frequently wideranging viewpoints that are actualized within a collective. The readers are invited to participate in and extend conversations across differences. This article provides a productive illustration of and about feminist work in solidarity to differences. It offers important ways to think differently, not only with regards to feminism, but also to writing practices and educative spaces.

The fourth and final article in this issue is entitled "The Final Cut?: The Production of pedagogy and scholarship within a society of control" authored by Erin Adams, Stacy L. Kerr and Elizabeth Ann Wurzburg from the U.S. Readers are invited to participate in a collective research process, also 
inspired by Deleuze and Guattari (1972/2009) and specifically framed by post-qualitative approaches that are framed as "methodology-to-come". Through Three minute Theory voice-over video creations, a visual text is created to introduce theoretical ideas, for example: What are societies of control? The script-writing processes, which result in videos linked within the authors article, are exemplified throughout the text to illustrate the entanglements between the generative coming together of theory, pedagogy and ideas. Additionally, Adams, Kerr and Wurzburg use the figure of the rhizome to describe their collaborations and collective writing processes, as intertwined productions reaching beyond themselves as authors. Through this example, the pedagogical decisions and the "cuts" of the material as well as the social conditions embedded within the making of the video stress the need to open up for the messiness that characterizes the processes of producing pedagogical tools. The authors are also careful to remind the reader that since pedagogues will never be sure of the direction their pedagogy will take, or what outcomes it may produce in the entanglements with students, they should remain open to what more the messiness can potentiate.

Editors, Lotta Johansson, Jayne Osgood, Camilla Andersen and Ann Merete Otterstad 